\title{
Adaptable Low Cost Shop-Floor Control System for Central and East European Companies
}

\section{J.Uhl}

ISW, University of Stuttgart

Seidenstr. 36, 70174 Stuttgart, Germany

tel. +497111212343, fax: +497111212413

e-mail: joachim.uhl@isw.uni-stuttgart.de

\section{Z.Smalec, J.Chrobot, J.Rakowski}

ITMiA, Technical University of Wroclaw

Lukasiewicza 3/5, 50-371 Wroclaw, Poland,

tel. +48 (71) 32038 78, fax: +48 (71) 210670 ,

e-mail: \{zbyszek,robot, rakos\}@itma.pwr.wroc.pl

\begin{abstract}
Industrial production in Central and East European countries is characterised by low productivity. An improvement of the situation would be achieved by a more effective application and use of existing resources and equipment as well as introducing a computeraided information flow. Shop-floor control systems play an important part as solution to these problems. This paper contains the goals and current results of the Copernicus project „Adaptable Low Cost Shop-Floor Control System" supported by the European Community. The goal of this project is to develop a low-cost shop-floor control system which should be adaptable in many different Central and East European companies. The first stage of this project has already been finished. The paper contains conclusions after implementation of this project stage.
\end{abstract}

Keywords

shop-floor control system, control system, software engineering, adaptation methods, low-cost 


\section{INTRODUCTION}

Shop-floor control systems can be assigned to the Computer Aided Manufacturing Area according to Figure1 (Pritschow, Uhl, 1995). Shop-floor control systems' tasks are the capacity planning of production units, the detailed planning of orders released by the Production Planning and Control (PPC), release of orders, as well as recording and evaluation of responses from the shop. With this the rough scheduling stated by the PPC is carried out and compressed data about the orders process are returned to the PPC (Eversheim, 1990; Nedeß, 1993).

Since changing to a free-market company, there is a need for effective production coordination and monitoring by shop-floor control systems in Central and East. European companies. Unfortunately, the market offers above all expensive shop-floor control systems having large extent of functions.

The contents of this article are therefore concerned with the structure and development of a shop-floor control system in an EC supported project that corresponds to the requirements of Central and East European companies.

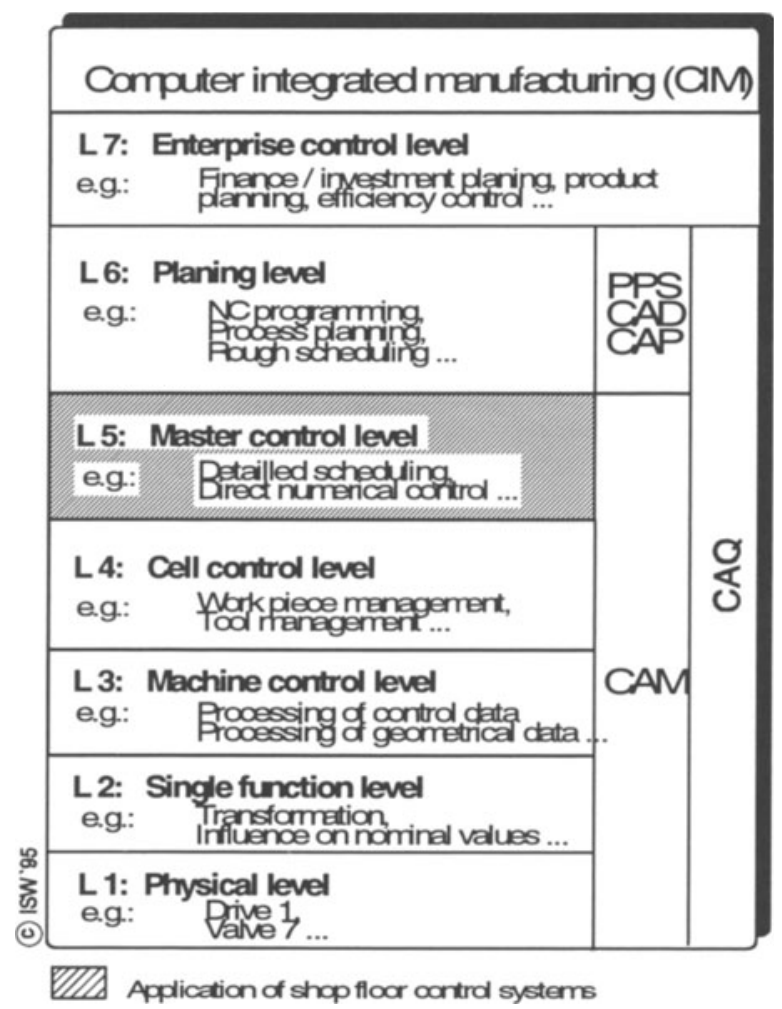

Figure 1: Categorisation of shop-floor control systems. 


\section{PROBLEM STATEMENT AND REQUIREMENTS OF A SHOP- FLOOR CONTROL SYSTEM FOR CENTRAL AND EAST EUROPEAN COMPANIES}

\subsection{Problem statement in Central and East European companies}

Decades of planned economies and lacking market-economy thought in Central and East European companies led to the following problems which have to be considered in the introduction and use of shop-floor control systems:

- The current production companies came, for the most part, from large centrally controlled combines. The out-dated and hard-to-understand organisation structures and information flow in the companies have remained intact due to rigid structures and are now slowly changing. A reorganisation for improving company processes and information flow is usually necessary before introducing control systems.

- A wide use of computer applications, as is common in all areas in Western European companies, is not present in East European companies. This is also true to the same extent for the level of worker training in using computer applications. An introduction of shopfloor control systems must therefore generally be in connection with intensive training of the workers.

- A chronic lack of capital does not allow for the purchase of shop-floor control software that fits the requirements, and therefore expensive, from Western European companies.

\subsection{Problems with the introduction and use of purchasable shop-floor control systems in Central and East European companies}

Investment in capital-intensive plants to be able to have high quality production, requires effective planning, control and monitoring of production. The last part requires use of software solutions for shop-floor control systems. However, the introduction and use of purchasable shop-floor control systems has the following problems:

- Good-value, requirement-sized PC solutions with low functionality and that are highly modifiable are not available in the West.

- Shop-floor control systems are usually not offered in the relevant local language or are poorly translated. They are usually not user-friendly, so the user needs a considerable amount of time to become familiar with them as hardly any basic knowledge can be expected.

- The shop-floor control system introduction costs from Western European companies are very high. East European marketing companies sometimes have neither the respective systems nor sufficient knowledge for an integration of the shop-floor control system.

- In Central and East Europe the information flow and the organisation of companies from the same product area differ more than in the West, therefore more adaptation of a shopfloor control systems is necessary. 
- An integration of shop-floor control systems usually proves to be difficult, especially when software solutions which already exist in the companies, must be considered. This is because either self-developed solutions or simply closed software solutions were implemented which do not have the required interfaces.

- Organisational improvements and product technology improvements require a high flexibility, adaptability and extendibility of a shop-floor control system, which is generally not currently available.

\subsection{Requirements of a shop-floor control system for Central and East European companies}

For the above problems, requirements of a shop-floor control system for Central and East European companies can be derived from Figure 2.

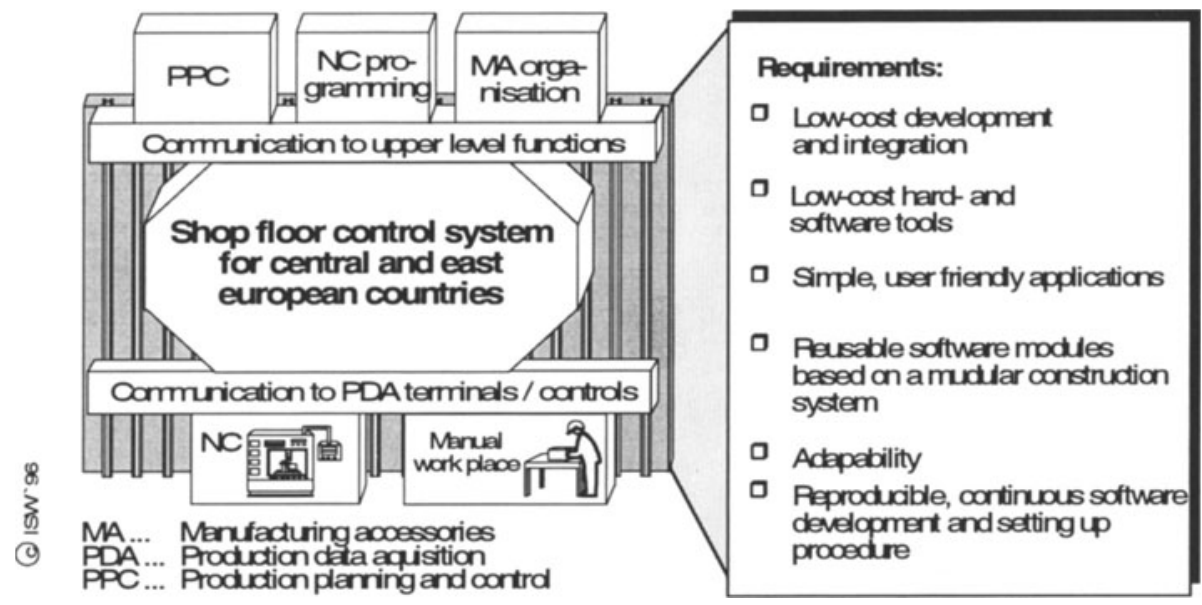

Figure 2: Requirements of a shop-floor control system for Central and East European companies.

An important criteria for the shop-floor control system is low costs. This means low costs development, the costs which influence the licensing costs for the shop-floor control system, costs of integration and introduction as well as the necessary hardware and software tools. Therefore a software solution is planned with limited functionality with only the minimum necessary functionality. Using the shop-floor control system on a PC is strived for with limited costs for the additionally needed software, for example, for the operating system or database.

User interfaces and callable functions must be kept simple and self explanatory. A simple software adaptation of the shop-floor control system must be guaranteed. Beside the simple adaptability on various operating systems and hardware environments, this also concerns an 
adaptability to various organisational structures and information flows. A change by improving the structures must be considered especially. For this, various adaptability methods (Brantner, 1993; Siewert, 1994, Pritschow and Uhl, 1994) should be used.

Additionally, a systematic procedure must be defined for an initial development as well as adaptation development for integrating and set-up of software for a shop-floor control system. This is needed to be able to carry out a quick, simple and inexpensive set-up of the shop-floor control system based on company specific requirements and the results of a company analysis, for example by parameterising and especially also adaptability development for integration (Pritschow and Uhl, 1994; Siewert, 1994). This has to be done in a repeatable manner so that the master control system is not the individual expertise of the respective developer, but rather that adaptation developments may also be carried out by reasonably priced workers.

\section{FUNCTIONS OF THE SHOP-FLOOR CONTROL SYSTEM}

According to Figure 3, the functions of a shop-floor control system can be differentiated as the following functions:

- managing
- planning
- operative.

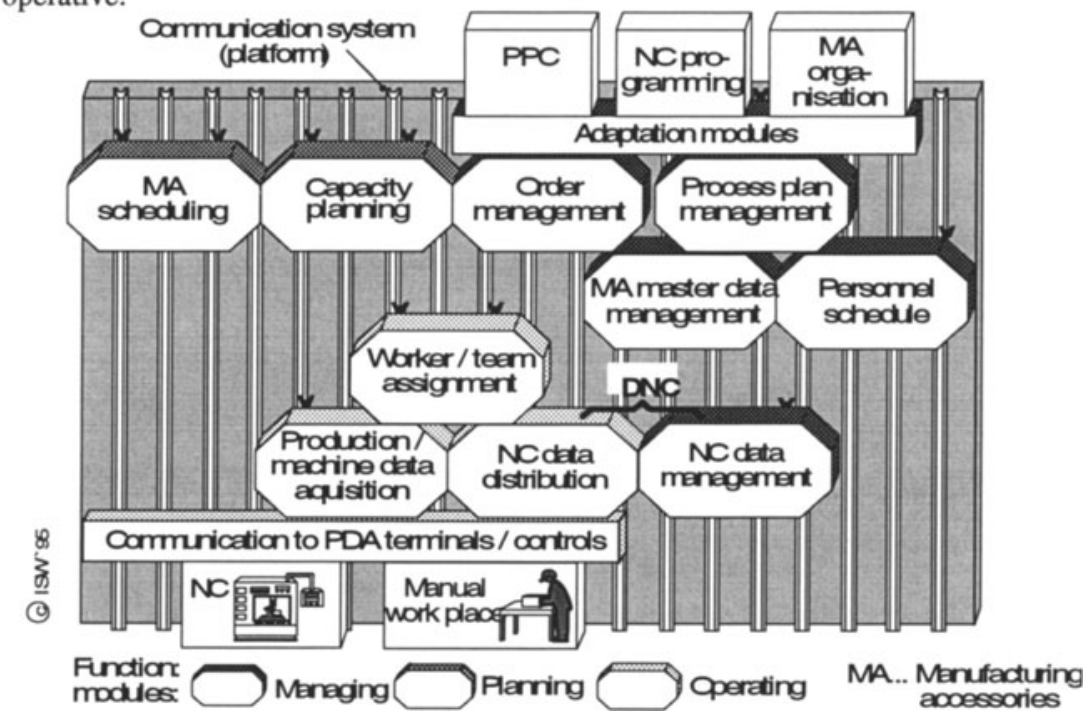

Figure 3: Functions of a shop-floor control system.

The functions are each shown separately in function modules. The structuring occurs in a way that the modules are, to a large degree, autonomous and can operate in parallel. With this 
modular formation it is possible to independently use single components or to swap out components for changed requirements.

Characteristic functions of a shop-floor control system are:

- order management: management of production orders with piece numbers, planning horizon and tracking order advancement;

- process plan management: management of work-piece related process plans and the order of production steps, production alternatives and affiliated manufacturing accessories;

- capacity planning: detailed planning of production orders on machines or manual work places, creation of (machine) load plans;

- personnel calendar: management of shift plans;

- manufacturing accessories scheduling: order specific demand of manufacturing accessories such as e.g. tools, pallets and fixtures, manufacturing accessories set-up and availability check;

- manufacturing accessories management: management of master data for types of manufacturing accessories types and data for single manufacturing accessories;

- worker-team assignment: order release and order assignment to teams and individual workers, simple order processing;

- production data acquisition: recording, protocolling, and forwarding of process reports, display of plant status, interruptions and transporting, evaluation of messages;

- NC data activation: loading and receiving NC programmes, corrections and zero point changes to the NC machines, starting the program;

- NC data management: management of NC programs and offset values of tools and pallets.

\section{ADAPTABILITY METHODS OF A SHOP-FLOOR CONTROL SYSTEM}

Adaptability methods are aids and mechanisms which make it possible to fit a shop-floor control system to the requirements of another company without changing the software or by only making small changes, or developments, to the software. By using adaptation methods the introduction of a shop-floor control system limits itself extensively to one initiation (see also chapter 5). This way, further developmental work on the shop-floor control system is avoided. Adaptability methods have to be considered in the development of a shop-floor control system. Figure 4 shows a list of adaptability methods.

Standards simplify the portability of software, especially user interfaces and database access on other computers or on other operating systems.

Development platforms with software libraries free the software engineer from routine programming and he may use tested software which is of higher quality. Additionally, operating system specific functions and database specific functions are encapsulated. Also, using a development platform and software libraries, portability is increased. This especially 
concerns procedure calls for communication between function modules as well as other operating system calls in function modules.

Configuration simplifies the step by step extension of a shop-floor control system with function modules and allows a simple exchange or an individual assembly of the master control system according to needs.

Parameterising data increases the flexibility and the area of use of the function modules without needing changes in the software of the function module.

Adaptation modules simplify the connection of the shop-floor control system with other systems, i.e. a PPC-system, without changing the software of the shop-floor control system. Software development work is needed for adaptation modules for new uses.

\begin{tabular}{|c|c|}
\hline 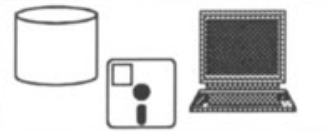 & $\begin{array}{l}\text { Standards such as SC, X Mndons, Motif, } \\
\text { Unix, } \mathrm{Cl}++\end{array}$ \\
\hline & $\begin{array}{l}\text { Software development platform with libraries } \\
\text { for comm nication, data bese, memory mena } \\
\text { gement, error logging, etc. }\end{array}$ \\
\hline DA & Configuration of function modules \\
\hline (CP) $\begin{array}{l}\text { madsine } \\
\text { tods } \\
\text { machine hour } \\
\text { rate, etc. }\end{array}$ & Parameterising of function modules \\
\hline (OM) (CP) & $\begin{array}{l}\text { Adaption modules to external software } \\
\text { systems }\end{array}$ \\
\hline
\end{tabular}

PDA ... Production data aquisition PPC... Production planning and control OM... Order management OP... Capacity planing

Figure 4: Adaptability mechanisms for shop-floor control systems.

\section{PROCEDURES FOR AN INITIAL DEVELOPMENT OR ADAPTATION DEVELOPMENT AS WELL AS SET-UP}

The following chapter describes the procedure for developing and setting up the shop-floor control system. It is shown how a systematic continuous procedure saves time and costs in the initial development and in the following use of the shop-floor control system. It also shows how a reproducible, documented development process the integration and set-up of the shopfloor control system is simplified and no longer must be carried out by the developer of the shop-floor control system. 


\section{Requirements analysis}

In the requirements analysis (see Figure 5) the organisational structure and the information flow of the individual company are investigated. This occurs with emphasis on the area or areas in which the shop-floor control system is to be introduced. The goal of the requirements analysis is to make:

- company schemes and

- process chain diagrams

of the company and the affected areas. This model was represented by a self developed notation (Copernicus, 1995). The notation contains:

- company schemes for hierarchical representation of the organisation structures and information flows;

- process chain diagrams in order to show functions, data and processes within the organisation units defined in the company schemes.

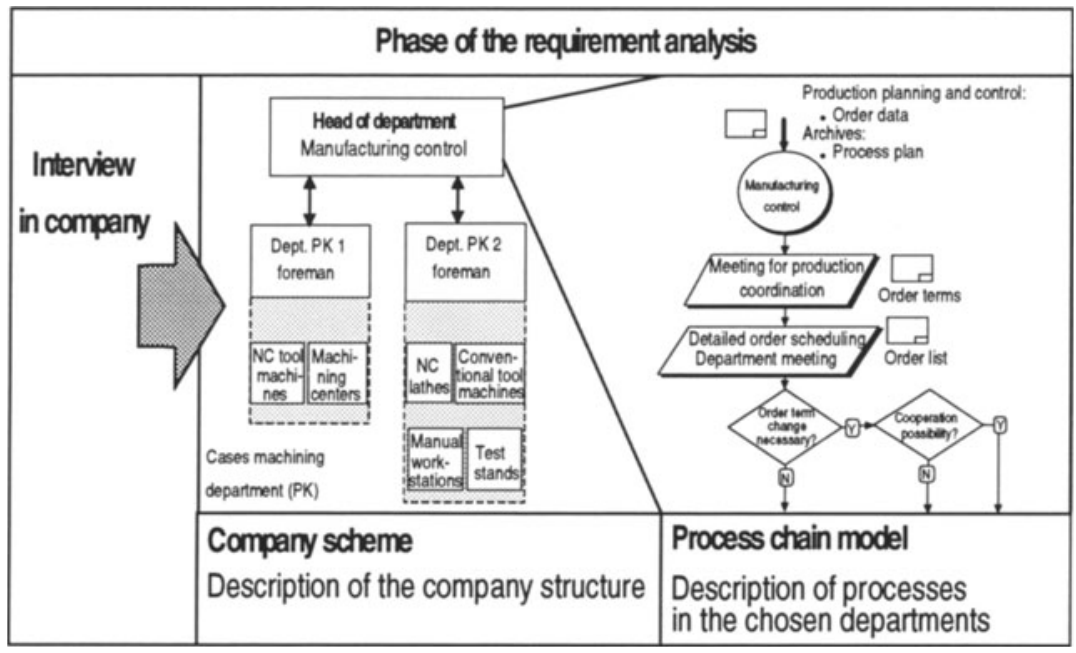

Figure 5: Requirement analysis phase.

From this model one can:

- derive the required data flow and functions as well as interfaces by comparing it to a reference model for the developed shop-floor control system and in agreement with the client;

- determine the weak points in the organisation and information flow in order to incorporate suggestions for improvement. 


\section{System analysis}

Starting from the company schemes and the process chain diagrams from the requirement analysis, in the system analysis an abstract model of the software is constructed in agreement with the client. As a description method (see Figure 6) the following is selected:

- structured analysis describing the functions of the data flow and the interface of the shopfloor control system (DeMarco, 1978);

- the Entity-Relationship-Method for describing the database structure (Chen, 1976).

Data flow and the essential functions may be derived from the company schemes and process chain diagrams. In resulting uses the software analysis model serves agreements with the client and to determine the possible expansion development or adaptation development. Configuration and parameter possibilities as well as the use of adaptability functions are established in this phase.

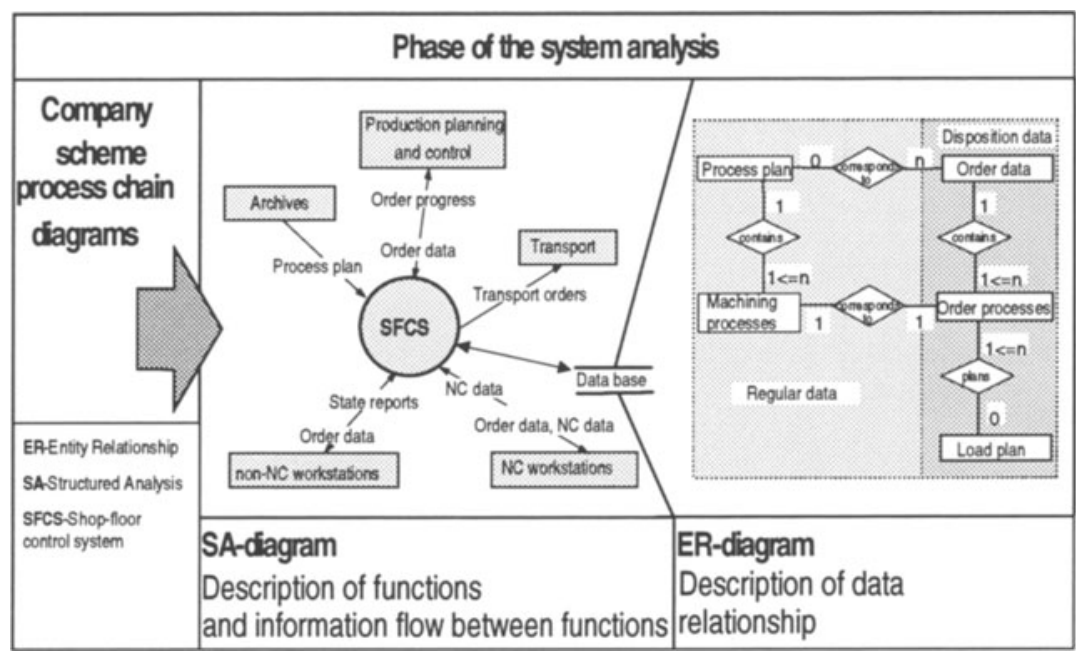

Figure 6: System Analysis Phase.

\section{System design, coding and testing}

The goal of this phase (Figure 7) is to convert the functions of the shop-floor control system and data flows from the system analysis into computer processes and to design these processes. For description methods the following are used:

- process diagram for describing the computer processes of the shop-floor control system;

- structured design for describing the computer processes of the process diagram (Constantine and Yourdon, 1979);

- the Nassi-Shneiderman-structograms for describing procedures from the Structured design diagram (Nassi and Shneiderman, 1973). 
The process diagram here is a self developed description method which has also already been agreed upon on the development platform (see chapter 4) of the developed shop-floor control system (Copernicus, 1996). The computer processes and the telegram exchange between the computer processes were taken from the essential functions as well as from the data flow between these functions of the software model from the software analysis phase. In this phase those procedures are also defined which encapsulate the database access and the operating system access and assign them to a replaceable software library.

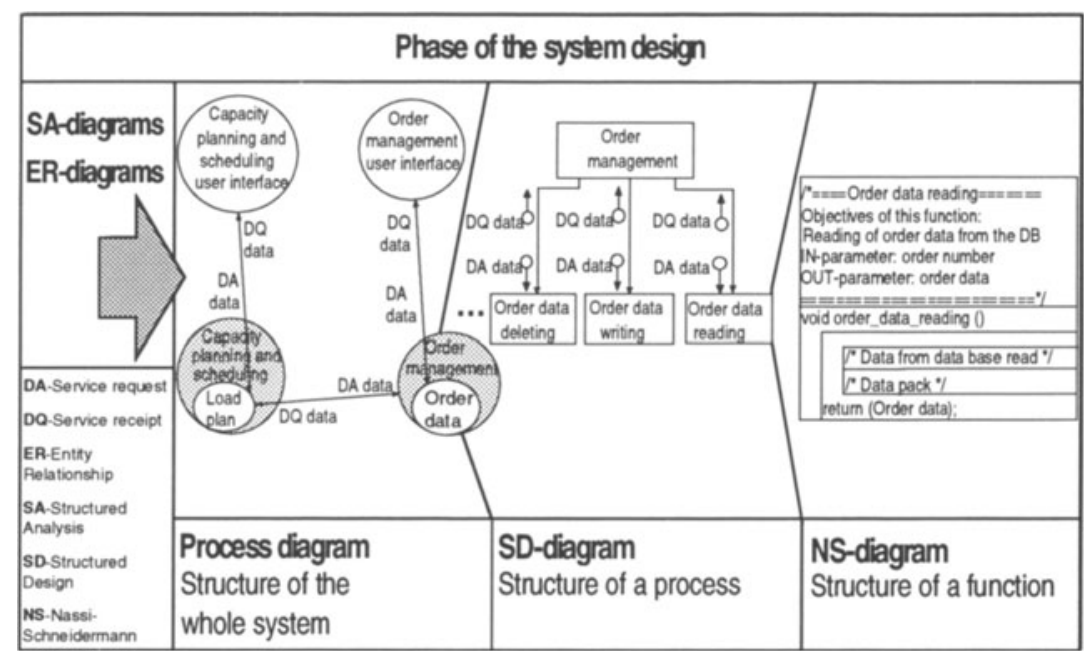

Figure 7: $\quad$ System design phase.

\section{Setting up phase}

When setting up, in addition to installation of the shop-floor control system, the software adaptation takes place. In this phase the shop-floor control system is configured and the individual modules used are parameterised. For adaptation to the computer, relevant software libraries must be integrated for operating system and database.

\section{IMPLEMENTATION EXAMPLE}

The three-year long, Copernicus project (no. CP9400337), started in March 1995, deals with the shop-floor control system described in the previous chapters. Three institutes are participating in the project. These are: the Institute for Control Technology for Machine Tools and Manufacturing Systems (ISW) of the University of Stuttgart in Germany, the Institute of Mechanical Engineering and Automation (ITMiA) of the University of Wroclaw in Poland, and the Institute for Machine Tools of the University of Prague in the Czech Republic. The companies PZL Hydral of Poland (producer of hydraulic pumps for general and specific uses), ZDAS of the Czech Republic (producer of rolling mill equipment and metal-forming 
machines) and PPS Detva of Slovakia (producer of fork-lift trucks among other things) are taking part in the project as industry partners and future users.

For example, at PZL Hydral the shop-floor control system shall be implemented in the production division for case machining (see Figure 8). Here the analysis of the organisation and information flow has already led to improvements such as the introduction of a validity period for technical documentation. It was also made clear that the use of the DNC is not yet sensible because of completely absent, or only partly available, DNC capable controllers.

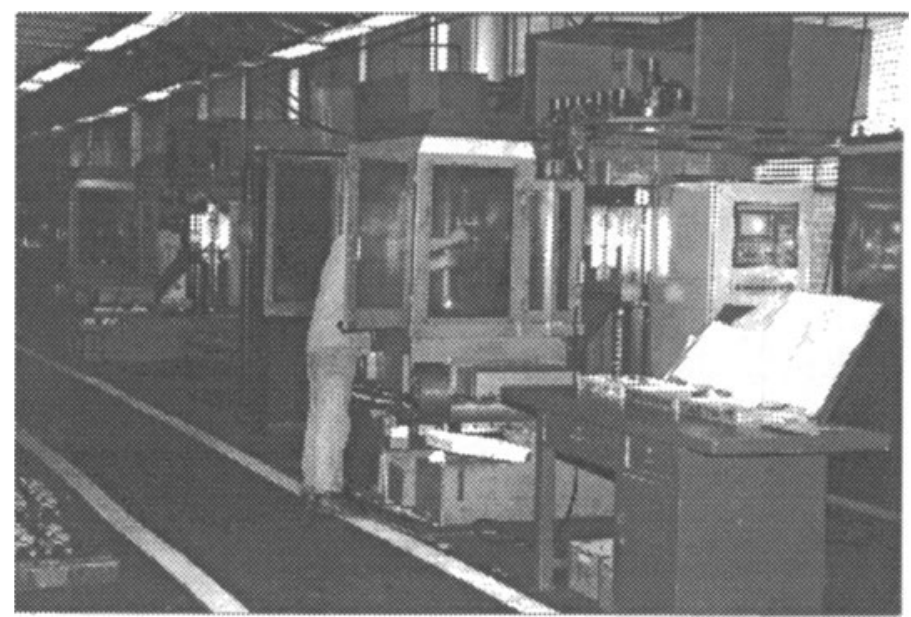

Figure 8: $\quad$ Case Machining Department at PZL Hydral, Poland.

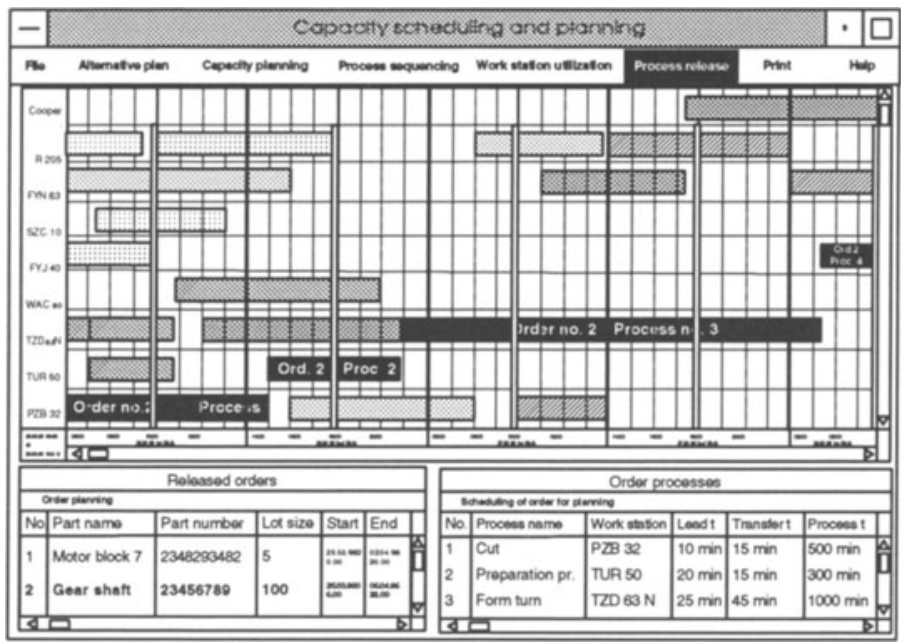

Figure 9: Graphical user interface for capacity planning and scheduling. 
Figure 9 shows a draft example of user interface of the workshop-control system. The figure illustrates the graphical user interface for capacity planning, which allows scheduling of orders for planning and release of processes to workers and teams assignment functions. The scheduling could be carried out manually, using graphical methods. There are also functions for capacity planning and process sequencing and also functions that allow work station utilisation and assembly line balancing to be reviewed.

\section{SUMMARY}

The preceding report shows the empirical values for developing and introducing a shop-floor control system for Central and East European companies within the EC-supported Copernicus Project. It became clear that in Central and East European companies only low priced, simply constructed and integratable and adaptable shop-floor control systems can be used. This is obtained by a PC based shop-floor control system structured in accordance with function modules and having a minimally needed functionality, and by using adaptability methods as well as with a systematic, reproducible development process. With this project it is possible to cover the needs Central and East European companies in accordance with a simple software support for the control and monitoring of their production, where simultaneously a transfer of expertise to East European engineers takes place.

\section{REFERENCES}

Brantner, K. (1993) Adaptierbares Leitsteuerungssystem für flexible Produktionssysteme. Dissertation Universität Stuttgart, Berlin, Heidelberg, New York: Springer Verlag.

Chen, P. P. S. (1976) The Entity-Relationship Model -Towards a Unified View of Data. ACM Transactions on Database Systems, Vol. 1, No. 1, pp. 9-36.

Constantine, L. L.; Yourdon, E., (1979) Structured Design. Englewood Cliffs, NJ: PrenticeHall.

Copernicus (1995) Copernicus CP940337 D1 Requirement analysis. WWW page address of the project: http://www.isw.uni-stuttgart.de/projekte/cp-sfcs/english/sfcs.htm

Copernicus (1996) Copernicus CP940337 D2.1-2.32 Design of Information system and DNC components.

DeMarco, T. (1978) Structured Analysis and System Specification. New York, NY: Yourdon Press.

Eversheim, W. (1990) Organisation in der Produktionstechnik, Band 1, Düsseldorf: VDIVerlag.

Nassi, I., Shneiderman, B. (1973) Flowchart Techniques for Structured Programming. SIGPLAN Notices, Vol. 8, 12 ff..

NedeB Ch., (1993) PPS und Lean Management: ein Gegensatz? TR, 16, pp. 20-23.

Pritschow G., Uhl J. (1994) The ALSYS adaptable control system for flexible production. Control Eng. Practice, Vol. 3, No. 1, 89-95.

Siewert U. (1994) Systematische Erstellung adaptierbarer Leitsteuerungssoftware am Beispiel der Durchsetzungsplanung, Dissertation Universität Stuttgart, Berlin, Heidelberg, New York: Springer Verlag. 


\section{BIOGRAPHY}

Joachim Uhl holds a master's degree in mechanical engineering. Since 1990, he has been working as research assistant at the Institute of control technology (ISW) at the University of Stuttgart. He is head of the group 'production control systems and quality assurance' and head of the COPERNICUS project 'Adaptable low-cost shop-floor control system' funded by the EC. His main research interests are the application of object-oriented techniques in flexible manufacturing, the development of decentralised control systems and the development of open system architectures for cell controls.

Zbigniew Smalec has been holding a doctor's degree in mechanical engineering since 1982. Since 1991 he has been senior lecturer at the Department of Machine Tools and Automation at the Institute of Mechanical Engineering and Automation (ITMiA), Technical University of Wroclaw, Poland. Since 1994 he has been member of Polish Association of Mechanical Engineers. He is head of Research Group for Control and Technology at the Institute of Mechanical Engineering and Automation. His scientific activity are overall about 40 publications in journals and conferences and numerous research projects for industry. His main research interests are tool machining processes, the application of industrial communication nets and control systems.

Jaroslaw Chrobot holds master's degree in automation and robotics. In the year 1992-1993 he has studied at the University of Stuttgart, Germany. Since 1994 he has been $\mathrm{PhD}$ student at the Institute of Mechanical Engineering and Automation, Technical University of Wroclaw (Poland) in the Research Group for Control and Technology. He has been working on the COPERNICUS project 'Adaptable low-cost shop-floor control system' funded by the EC. His main research interest is development of shop-floor control systems.

Jaroslaw Rakowski holds master's degree in automation and robotics. In the year 1992-1993 he has studied at the University of Stuttgart, Germany. Since 1994 he has been PhD student at the Institute of Mechanical Engineering and Automation, Technical University of Wroclaw (Poland) in the Research Group for Control and Technology. He has been working on the COPERNICUS project 'Adaptable low-cost shop-floor control system' funded by the EC. His main research interest is application of shop-floor control systems. 